\title{
A regionalização do turismo no litoral do Paraná (Brasil): análise da rede de interação entre os stakeholders ${ }^{1}$
}

\author{
The Regionalization Of Tourism In The Coast Of Paraná (Brazil): Analysis Of The Network Formed By The \\ Stakeholders
}

La Regionalización Del Turismo En El Litoral Del Paraná (Brasil): Análisis De La Red De Interacción Entre Los Stakeholders

Este artigo foi recebido em 21 de DEZEMBRO de 2018 e aprovado em 30 de JULHO de 2019

Jose Elmar Feger ${ }^{2}$

Cinthia Maria de Sena Abrahão ${ }^{3}$

Jose Manoel Gonçalves Gândara (In memorian $)^{4}$

Carlos Rogelio Virgen Aguilar ${ }^{5}$

Resumo: A temática abordada no artigo tem como input as relações entre atores envolvidos no processo de implantação da política de regionalização do turismo no Paraná. O objetivo principal foi analisar a relevância dos atores sociais na configuração do turismo da Região Turística Litoral do Estado do Paraná, tomando como referência o nível de relacionamento ocorrido entre eles. A investigação se pauta no referencial teórico metodológico da análise de redes sociais (ARS). Mediante o objeto de estudo, a investigação se caracterizou como de campo, com conotação exploratória, descritiva e quantitativa, sendo, do ponto de vista da abrangência temporal, classificada como crosssectional. O tratamento e a análise dos dados ocorreram com uso dos softwares UCINET e NETDRAW. Foram analisados: densidade das relações, níveis de centralidade e grau de relações existentes na área de abrangência da região turística, objeto desse estudo. $\mathrm{Na}$ análise de resultados, fica destacado o reduzido grau de consistência da rede, o índice de $2,4 \%$ indica a baixa densidade de relacionamento entre os atores entrevistados. No que diz respeito aos atores identificados como intermediários das relações entre os demais protagonistas regionais, destacam-se a Prefeitura Municipal de Guaratuba $(0,634)$, Prefeitura Municipal de Pontal do Paraná $(0,317)$, Associação Comercial de Guaratuba (ACIG) (0,211), Associação de Desenvolvimento do Turismo (ADETUR) $(0,106)$ e Associação Comercial de Antonina (ACIA) $(0,053)$. Conclui-se que, apesar de não possuírem um grau de centralidade significativo, as municipalidades revelam-se importantes elos entre os atores regionais. Além disso, observa-se pouca representatividade da instância de governança, que fica em quarto lugar no ranking dos atores identificados como pontes entre os demais envolvidos com o turismo regional.

Palavras-chave: Política Pública; Redes Sociais; Região Turística Litoral Paraná (Brasil); Turismo.

\footnotetext{
${ }^{1}$ O eterno agradecimento dos autores ao Dr. José Gândara (Zé) por seu empenho, colaboração, incentivo, amizade, exemplo e auxílio em tantas jornadas e produções.

${ }^{2}$ Informações do autor:

Formação/curso: Doutor em Desenvolvimento Regional. Instituição: Universidade Federal do Paraná - UFPR, PR, Brasil. E-mail: elmar.josefeger@gmail.com

${ }^{3}$ Informações do autor:

Formação/curso: Doutora em Geografia. Instituição: Universidade Federal do Paraná - UFPR - PR, Brasil. E-mail: cisena01@ gmail.com

${ }^{4}$ Informações do autor:

Formação/curso: Doutor em turismo sustentável. Instituição: Universidade Federal do Paraná - UFPR - PR, Brasil. E-mail: jmggandara@yahoo.com.br

${ }^{5}$ Informações do autor:

Formação/curso: Doctorado en Ciencias en Desarrollo Sustentable. Instituição: Universidad de Guadalajara -México. E-mail: carlosvirgen01@gmail.com
} 


\author{
A REGIONALIZAÇÃO DO TURISMO NO \\ LITORAL DO PARANÁ (BRASIL): ANÁLISE DA \\ REDE DE INTERAÇÃO ENTRE OS \\ STAKEHOLDERS
}

Jose Elmar Feger

Cinthia Maria de Sena Abrahão

Jose Manoel Gonçalves Gândara

Carlos Rogelio Virgen Aguilar

\begin{abstract}
The theme addressed in the article has as input the relations between actors involved in the process of implementation of the regionalization policy of tourism in Paraná. The main objective was to analyze the relevance of social actors in the tourism configuration of the Região Turística Litoral do Estado do Paraná, taking as reference the level of relationships between them. The research is based on the methodological theoretical framework of the analysis of social networks (ARS). Through the object of study, the research was characterized as of field with an exploratory, descriptive and quantitative connotation being, from the point of view of temporal comprehension, classified as cross-sectional. The treatment and analysis of the data occurred with the use of the software UCINET and NETDRAW. We analyzed: density of relations, levels of centrality and degree of relations existing in the area of coverage of the tourist region under study. In the analysis of results the low degree of network consistency is highlighted, the index of $2.4 \%$ indicates the low density of relationship among the interviewed actors. With regard to the actors identified as intermediaries of relations between the other regional protagonists, the Guaratuba City Hall (0.634), Pontal do Paraná city hall (0,317), Guaratuba commercial association (ACIG) (0.211) stand out, Associação de Desenvolvimento do Turismo (ADETUR) $(0,106)$ and Antonina commercial association (ACIA) $(0.053)$. It is concluded that although they do not have a significant degree of centrality, municipalities are important links between the regional actors. Moreover, there is little representation of the governance body, which is in fourth place in the ranking of the actors identified as bridges among the others involved with regional tourism.
\end{abstract}

Key words: Public policy; Região turistica litoral do Paraná (Brazil); Social networks; Tourism .

Resumen: La temática abordada en el artículo tiene como input las relaciones entre actores involucrados en el proceso de implantación de la política de regionalización del turismo en Paraná. El objetivo principal fue analizar la relevancia de los actores sociales en la configuración del turismo de la Región Turística Litoral del Estado de Paraná, tomando como referencia el nivel de relaciones ocurrido entre ellos. La investigación se pauta en el referencial teórico metodológico del análisis de redes sociales (ARS). Mediante el objeto de estudio, la investigación se caracterizó como de campo con connotación exploratoria, descriptiva y cuantitativa siendo, desde el punto de vista del alcance temporal, clasificada como transverso. El tratamiento y análisis de los datos ocurrió con el uso de los programas UCINET y NETDRAW. Se analizaron: densidad de las relaciones, niveles de centralidad y grado de relaciones existentes en el área de cobertura de la región turística objeto de estudio. En el análisis de resultados queda destacado el reducido grado de consistencia de la red, el índice del 2,4\% indica la baja densidad de relación entre los actores entrevistados. En lo que se refiere a los actores identificados como intermediarios de las relaciones entre los demás protagonistas regionales, se destacan el Ayuntamiento Municipal de Guaratuba (0,634), Ayuntamiento Municipal de Pontal do Paraná (0,317), Asociación Comercial de Guaratuba (ACEP) (0,211), Asociación de Desarrollo del Turismo (ADETUR) (0,106) y Asociación Comercial de Antonina (ACIA) (0,053). Se concluye que, a pesar de no poseer un grado de centralidad significativa, las municipalidades se revelan importantes vínculos de conexión entre los actores regionales. Además, se observa poca representatividad de la instancia de gobernanza, que queda en cuarto lugar en el ranking de los actores identificados como puentes entre los demás involucrados con el turismo regional.

Palabras clave: Política Pública; Redes sociales; Región Turística Litoral Paraná (Brasil); Turismo. .

\title{
1.Introdução
}

O turismo pode ser entendido como um fenômeno social (DE LA TORRE, 1997) que ocorre, essencialmente, entre pessoas e lugares (PEARCE, 2003) cujos componentes chave são os turistas e destinos (PEARCE; SCHÄNZEL, 2013). Panosso Netto (2009) o descreve como um evento causado pelo movimento dos seres humanos, ao se ausentarem e regressarem a residência habitual por diversos motivos, acarretando hospitalidade e encontros. Segundo o referido autor, para que o ato de ir e vir seja possível, subentende o convívio com outras pessoas, tecnologias e empresas que oferecem

Observatório de Inovação do Turismo - Revista Acadêmica

Vol. XIII, n 3, dezembro - 2019 
serviços, cujo processo envolve experiências sensoriais e psicológicas, com efeitos positivos e negativos nos ambientes (sociocultural, político, econômico e ambiental) nos quais ele acontece.

Para o desenvolvimento da atividade turística, nessa perspectiva, Gândara; Torres (2003) apontam, como premência, que os atores envolvidos estejam comprometidos com o planejamento, a implementação, o desenvolvimento, a gestão e o controle da operação de forma estratégica e sustentável. Destaca-se, portanto, a importância da descentralização e da concertação social em torno do processo turístico, implicando na necessidade de estruturas capazes de articular os atores em prol de um desenvolvimento responsável (GÂNDARA; TORRES, 2003).

Todavia, cogita-se que cada um dos atores possui interesses específicos ligados aos tipos de recursos existentes no destino turístico. Além dos recursos, há interesses específicos de cada agente, os quais são observados mediante os tipos de bens que desejam alcançar ou benefícios que podem conseguir por intermédio do desenvolvimento da atividade turística no destino. Tais benesses são medidas pela introdução de novos capitais (econômicos, sociais e culturais) no destino. (PIMENTEL; PIMENTEL, 2012).

Observa-se tais parâmetros no Programa de Regionalização do Turismo, parte integrante da Política Nacional do Turismo (PNT), especialmente no atinente a ênfase dada a descentralização da gestão por meio das instâncias de governança regionais, aderindo a lógica do desenvolvimento endógeno (BRASIL, 2013). Ao estipular a regionalização como técnica de conformação do turismo para fins de planejamento e gestão, o Ministério do Turismo sublinha que, com essa disposição espacial, a oferta adquire maior significância e identidade devido a qualidade e originalidade que tal arranjo agrega ao serviço (BRASIL, 2015).

Nessa linha de raciocínio, a literatura científica indica que o desenvolvimento regional do turismo está relacionado a diligência com que os atores locais estabelecem relações entre eles a fim de elaborar ações conjuntas e coordenadas para a melhora das condições do território e maior possibilidade de alcançar êxito nos objetivos de desenvolvimento propostos (RODRÍGUEZ; FERNÁNDEZ, 2009). Assim, concebe-se que assimilar e interpretar as relações e o valor a elas (relações) atribuídos pelos atores locais é essencial para a caracterização da atividade turística do território.

Diante disso, o principal objetivo da Análise de Redes Sociais (ARS) é entender a articulação entre os atores que atuam em determinado espaço ou ambiente social. Seu arcabouço teórico pode ser aplicado para compreender as interações que ocorrem entre atores públicos e privados de uma região. 
A ARS permite identificar a importância que cada um deles possui na região, sua função e qual é o seu nível de interação com os demais. Atualmente, é possível analisar esses dados por meio de gráficos e estatísticas geradas por softwares, dentre os quais estão o UCINET e o NETDRAW.

A utilização da metodologia de ARS vem crescendo nos últimos anos (XAVIER, 2012; FREIRE et al, 2014; FEGER, ABRAHÃO, ETGES, 2015; KÖRBES, FEGER, 2018). Ela envolve várias áreas do conhecimento e tem como principal resultado criar uma rede de conhecimento comum entre elas, ofertando mecanismos que almejam identificar os comportamentos de atores, tanto públicos como privados, em vários aspectos, principalmente em suas relações entre si. O elemento fundamental da rede social são os atores, ou "nós" que representam pessoas ou organizações. A partir disso, estabelecem-se os relacionamentos, denominados ligações. Portanto, a metodologia de ARS possibilita compreender de que forma agem os stakeholders em suas redes e como ocorre a cooperação entre eles para o compartilhamento das informações.

Em suas investigações, Vázquez (2013) corrobora a literatura e nomeia o termo stakeholder para identificar os atores, agentes ou partes interessadas que possam ter influência umas sobre as outras. O referido autor alude que a legitimidade dessa relação advém de uma percepção ou hipótese de que as ações de uma entidade são desejáveis e apropriadas de acordo com um sistema de normas, valores, benefícios e definições construídos socialmente.

Mediante o exposto, o principal propósito da presente investigação, consistiu em compreender e determinar a importância que os atores sociais possuem na configuração do turismo na Região Turística Litoral do Estado do Paraná, tomando-se como referência o nível de relacionamento ocorrido entre eles. As inferências e interpretações dos dados foram fundamentados na teoria das redes sociais. A pesquisa foi justificada pela oportunidade de aprofundar estudos voltados a organizações públicas e privadas atuantes no setor turístico e contribuir para a ampliação de conhecimento sobre esse campo. Ressalta-se ainda, como relevante, o uso da metodologia, que enfatiza o nível de relacionamento dos atores e seus impactos sobre o processo de desenvolvimento da região em que se encontram.

Tendo em vista os objetivos da pesquisa e considerando o suporte obtido por meio da revisão bibliográfica, foi realizada uma pesquisa de campo, na qual atores estratégicos, que atuam na região turística litoral do Paraná responderam perguntas relacionadas ao desenvolvimento do turismo na região. Foram considerados tanto atores públicos como privados, envolvendo secretarias de turismo municipais (ou fundações de turismo em vários casos), associações empresariais locais, de hotéis, agências de turismo, universidades e entidades representativas da sociedade civil. 
Os resultados analisados no artigo explicitam as redes identificadas, por meio das respostas de cada um dos atores pesquisados, no que tange aos estabelecimentos ou instituições com os quais realizam ou pretendem realizar trabalhos, conjuntamente, em prol do desenvolvimento turístico do município e da região. Os dados obtidos foram organizados em uma planilha Excel e depois transportados para o software UCINET, que propiciou extrair as informações relacionadas a densidade das relações, volume de atores centrais, grau das relações ocorridas entre os atores públicos quanto a bilateralidade, unilateralidade ou multilateralidade.

O texto está estruturado em quatro partes. Uma primeira que se constituiu desta introdução, na qual são apresentados os objetivos da pesquisa. Na segunda parte, marco teórico, apresenta-se a revisão da literatura que permitiu aprofundar os conhecimentos necessários à compreensão do objeto de estudo. Na terceira, consta a discussão dos métodos e procedimentos adotados para o levantamento de dados e a sua análise. Em seguida, apresentam-se os resultados alcançados e sua respectiva discussão. Finalmente, apresentam-se as considerações finais, destacando-se o aprendizado obtido, as considerações finais e a indicação de novas possibilidades para continuar a linha de investigação.

\section{Marco teórico}

O turismo, em sua face econômica, enquadra-se como parte do terceiro setor da economia e é formado pelo conjunto de serviços ofertados para o atendimento das necessidades de um tipo especial de consumidor, que são designados como turistas (BOULLÓN, 2002). A estrutura básica da atividade turística em um determinado local envolve: os atrativos da área, a qualidade dos serviços oferecidos aos turistas, a infraestrutura turística, a demanda de visitantes e os atores públicos e privados, formadores das redes, que têm a responsabilidade de coordenar as atividades do setor. (BOULLÓN, 2002; 2005). Por essa especificidade de configuração, em cada destino turístico identifica-se um conjunto de organizações que atuam em competição e outras em cooperação. No entanto, mesmo as primeiras possuem ao menos um elo de cooperação que é a sua promoção e manutenção.

Para que o turismo tenha impacto positivo no ambiente em que está inserido, é necessário que os atores locais participem ativamente da rede. O envolvimento deles entre si, agindo para garantir e promover uma constante inovação na oferta turística e, também, se preocupando em diminuir a diferença social, tende a promover um desenvolvimento significativo para a região (MARTINS et al., 2009). A construção da identidade regional está intimamente relacionada à articulação de atores locais, bem como à sua capacidade de formação de redes cooperativas, conforme indicam Bernardes et al. 
A REGIONALIZAÇÃO DO TURISMO NO

LITORAL DO PARANÁ (BRASIL): ANÁLISE DA REDE DE INTERAÇÃO ENTRE OS STAKEHOLDERS
Jose Elmar Feger

Cinthia Maria de Sena Abrahão

Jose Manoel Gonçalves Gândara

Carlos Rogelio Virgen Aguilar

(2006). As entidades formadoras das redes turísticas podem ser: políticas, econômicas e sociais, e essas devem ter como principal aliada a comunidade, pois ninguém conhece melhor o ambiente que seus habitantes.

Conforme Putnam (1996) e Fisher (2004), a rede desempenha um papel essencial no desenvolvimento político e socioeconômico de cada região. Nesse contexto, surgem muitas estratégias que favorecem os atores presentes no território, bem como a comunidade. Tais estratégias se caracterizam principalmente por sua flexibilidade, estrutura dinâmica, horizontalidade, e um grau elevado de autonomia dos seus membros. Trata-se, pois, de uma perspectiva centrada nos atores e que assume como pressuposto que processos e campos de relação devem ser colocados em tela como elementos dinamizadores e promotores do desenvolvimento. Schmitt (2011) acrescenta, ainda, que os vetores externos, provenientes do Estado ou do mercado, requerem ressonância no âmbito da comunidade, introjeção por parte dos atores para afetarem as oportunidades.

A rede em sua estrutura possui alianças estratégicas, os atores privados procuram complementar-se nos planos técnicos e comerciais (OLAVE; AMATO NETO, 2005), o que possibilita oferecerem vantagens em termos de custos relativos ao processo de inovação, aumentando a eficiência econômica e minimizando a competitividade. Ao serem organizadas a partir de interesses empresariais, tendem a possuir centralidades, representadas por empresas polarizadoras da atividade produtiva, no contexto analisado. Norteada pelo mesmo princípio das alianças estratégicas, existem as Redes Estratégicas Regionais (RER), cuja formação está associada ao propósito do desenvolvimento regional, o que constitui seu primeiro aspecto distintivo. Além disso, em geral, são redes que contam com a participação de Universidades e/ou de agências governamentais (LUNDBERG, 2011)

É intrínseco às RERs que elas atuem com base no princípio da coopetição, conceito ainda insuficientemente esgotado na literatura de gestão e de estratégia, considerando que existe ênfase mais efetiva sobre os extremos, competição e cooperação. Todavia, quando se trata desse tipo de estrutura, observa-se que atores que possuem suas estratégias de competição, também conseguem vislumbrar oportunidades em estabelecer outras que envolvem cooperação. Em geral, os objetivos centrais continuam delineados pela necessidade de ampliar sua capacidade de atender o mercado, obtendo ganhos de escala, redução de custos, e, particularmente, no caso do turismo, pode-se inferir os ganhos de atratividade para os destinos em que tais redes são articuladas. Ritala (2012) explicita a geração de potencial inovativo, a viabilização de estratégias coletivas de inovação e o estabelecimento de um ambiente propício ao aprendizado como os grandes derivados dos processos colaborativos. 
A REGIONALIZAÇÃO DO TURISMO NO

LITORAL DO PARANÁ (BRASIL): ANÁLISE DA REDE DE INTERAÇÃO ENTRE OS STAKEHOLDERS
Jose Elmar Feger

Cinthia Maria de Sena Abrahão Jose Manoel Gonçalves Gândara Carlos Rogelio Virgen Aguilar

Balestrin; Vershchoore e Reyes Júnior (2010; 2016) identificam que, em termos de operacionalização das RERs, é necessária a utilização de ferramentas específicas de gestão, sejam elas de estratégia, de estrutura ou de processos. Todavia, identificam que tímidos avanços no Brasil, no que tange ao monitoramento de rotinas de marketing, expansão e negociação, formação de lideranças, têm sido registrados. Tal parece refletir o comportamento organizacional de entidades de pequeno porte, nas quais esses aspectos, em geral, são relegados a segundo plano.

Ainda no que tange a coopetição, Santaloya-Sans et al (2017) discutem dois aspectos relevantes e que precisam ser considerados quando se analisa uma RER que são: a) o caráter contraditório e conflituoso da relação dos stakeholders; b) de outro lado, a necessária capacitação para coopetir. Ao tempo que a competição gera tensões e forças dissipativas, a coopetição requer estratégias de gestão dessas inquietações para tornar produtivo o arranjo, no sentido de possibilitar que se atinja seus potenciais, teoricamente explicitados.

Entende-se que a identificação de redes sociais possibilita que se conheça o ambiente sobre o qual pretende-se o desenvolvimento de uma RER, permitindo saber quais são os atores, além de contribuir para o conhecimento das atividades empreendedoras e do potencial de inovação da região. Segundo Ferrão (2002), a produção do conhecimento depende do nível de interação e de interesse em toda fase dos processos dos atores participantes da rede. Nesse sentido, Chim-Miki e Batista-Canino (2017) destacam algumas especificidades que são pertinentes à aplicação do conceito e das práticas de gestão coopetitiva em atividades relacionadas ao setor de serviços, como é o caso do turismo. As autoras indicam que quanto maior o grau de cultura comum e de valor compartilhado, maior a tendência ao compartilhamento de recursos, conhecimento e trabalho. Destacam, ainda, que a confiança mútua constitui um termômetro para a realização das ações, para a própria implantação da rede: “[...] quando os empresários têm consciência das vantagens do partnering, as associações empresariais são mais representativas" (p.222).

Segundo Pimentel e Pimentel (2012), o turismo é o resultado de diversas ações feitas por diferentes organizações, as quais precisam ser organizadas e integradas, pois não funcionam isoladamente. O destino turístico, como afirmam Chim-Miki e Batista-Canino (2016), pode ser considerado como um sistema de coopetição, o que permite pensá-lo para além da lógica econômica da oferta e demanda e mesmo da ótica da competitividade empresarial. A governança turística, por sua vez, representa o modelo inovador de gestão, especialmente, porque expressa o desafio da gestão coopetitiva. As mesmas autoras identificam que ao serem administradas por instâncias intermediárias, 
tal como associações comerciais, as redes turísticas tendem a apresentar melhores resultados (CHIMMIKI; BATISTA-CANINO, 2017).

Como instrumento para compreender as relações entre os agentes, a tradição da análise das redes sociais evoluiu ao longo do tempo, iniciando nos anos 1930, tendo contribuições de Jacob Levy Moreno nas décadas de 1940 e 1950, Allen Barton na década de 1960, Freeman (1978; 2004) para citar alguns. Para Burt et al (2013), uma das vantagens dos modelos de análise das redes sociais é que o objeto de estudo pode ser movido para diferentes níveis, podendo o ator ser um indivíduo, uma comunidade ou uma organização. Freeman (2004) assevera que a abordagem em rede social se fundamenta na noção de que o padrão de vínculos em que os atores estão inseridos tem consequências importantes para os mesmos. Nesse sentido, para esse autor, os analistas de redes procuram descobrir vários tipos de padrões e tentam determinar as condições mediante as quais esses padrões surgiram e elucidar suas consequências. Por meio desse paradigma teórico, Freeman (2004) aponta que podem ser encontradas quatro características principais na análise moderna de redes, que, juntas, definem o campo: a) análise de redes sociais é motivada por uma estrutura intuitiva baseada nos laços que ligam os atores sociais; b) baseia-se em dados empíricos sistemáticos; c) inspira-se fortemente na imagem gráfica; d) baseiam-se em modelos sistemáticos e/ou computacionais.

Mediante a discussão pretérita, presume-se que as redes são complexas e demandam instrumentos específicos para delimitar sua estrutura e obter os resultados pretendidos nos objetivos do estudo. Scott et. al. (2008) alegam que a análise de redes sociais se configura em um conjunto de técnicas integradas utilizadas para desenhar os padrões de relações e analisar a estrutura de troca de recursos entre os atores, sendo eles indivíduos, grupos ou organizações. Para esses autores, após a coleta de dados relacionais, os mesmos são organizados em uma matriz a fim de se calcular os vários parâmetros como densidade e centralidade.

De acordo com o entendimento de Alejandro e Norman (2005) apud (LIMA, 2018), os indicadores de centralidade possibilitam analisar a rede no seu conjunto e individualmente, apresentando diversos resultados: grau de conectividade da rede, indivíduos com maior e menor número de interações, intermediação de alguns atores nas relações entre indivíduos e a proximidade entre os indivíduos por meio das suas interações.

As redes podem ter muitos ou poucos atores e uma ou mais categorias de relações entre pares de atores. De uma maneira mais simples, uma rede é composta por três elementos básicos: nós ou atores, vínculos ou relações e fluxos (ALEJANDRO \& NORMAN, 2005, apud LIMA (2018). Nós ou 
atores correspondem às pessoas ou aos grupos de pessoas que se aglomeram com objetivos comuns. Habitualmente, são representados por círculos e a soma de todos os nós indica o tamanho da rede. Já os vínculos são os laços que existem entre dois ou mais nós. Normalmente, são representados por linhas. Quanto ao fluxo, indica a direção do vínculo a qual se representa com uma seta mostrando o sentido. Os fluxos podem ser unidirecionais ou bidirecionais. Vale destacar, que quando um ator não estabelece qualquer tipo de fluxo, indicando ausência de vínculos, admite-se que o nó está solto dentro da rede (LIMA, 2018).

Mediante esta discussão, entende-se que a densidade e a força de uma rede consistem na intensidade das conexões entre seus nós/atores, e pode ser calculada pelo número real de conexões dividido pelo número possível de conexões. Por essa razão, sugere-se que os modelos de rede estudam como se distribuem a informação em um sistema social (BURT et al 2013). Para Oliveira et. al. (2014), a análise de redes sociais tem como objetivo estudar os vínculos relacionais, considerando atores ligados uns aos outros por vínculos sociais. Eles afirmam que é possível identificar esses vínculos da seguinte forma: social (amizade); por associação e afiliação (clubes e associações); por interação profissional (trabalho, científica, tecnológica etc.); física (rede Internet, cidade, bairro etc.); biológico (família); dentre outros. No caso desta investigação, o foco se concentra nas interações profissionais.

Os fundamentos discutidos nesta seção orientaram os procedimentos de coleta e a análise dos dados que serão apresentados nas próximas seções deste artigo.

\section{Metodologia}

A presente investigação é caracterizada como do tipo exploratório-descritiva apoiada na abordagem de análise quantitativa dos dados. A pesquisa exploratório-descritiva busca o aprimoramento de ideias, intuições e propõe-se a retratar características de determinado cenário (GIL, 2010). Caracteriza-se como exploratória, segundo o mesmo autor, quando o exame possui como objetivo principal familiarizar o pesquisador com o tema de sua discussão. Gray (2012) corrobora este entendimento e completa dizendo que os estudos exploratórios aspiram examinar o que está acontecendo e questionar-se a respeito. Definem-se como estudos descritivos aqueles que têm como objetivo principal construir o panorama de uma situação, evento, pessoa ou até mesmo, evidenciar como os objetos de estudo estão relacionados entre si, não tendo a obrigação de explicar o motivo por trás do acontecimento propriamente dito (Gray, 2012). No caso desta investigação, pretende-se 
explorar e descrever as características das relações ocorridas entre os stakeholders envolvidos com a gestão do turismo na Região Turística Litoral do Paraná.

De posse dos dados, no que diz respeito ao seu tratamento, a pesquisa pode ser classificada como quantitativa, visto que, segundo Malhotra (2006), procura estimar determinado comportamento de uma população específica. Creswell (2012) aponta que dados quantitativos, tais como números e indicadores, podem ser analisados com auxílio da estatística e, assim, revelar informações úteis, rápidas e confiáveis a respeito de um determinado número de observações, os quais ajudam a mensurar de forma clara os itens pesquisados. Trata-se de um método de análise dos dados, que, segundo Gerhardt e Silveira (2009), tem como foco a objetividade, onde os resultados são tomados como a realidade da população alvo da amostra, recorrendo à linguagem matemática para descrever os fenômenos. No que se refere a presente pesquisa, envolve a quantificação das relações por meio de indicadores conforme os preceitos discutidos no âmbito das redes sociais.

A pesquisa empírica está fundamentada, portanto, na metodologia de Análise de Redes Sociais (ARS), cujos conceitos foram discutidos na seção anterior deste artigo. Devido ao fato de não haver dados anteriores que pudessem ser utilizados como referência, a proposta da atual pesquisa se caracterizou como cross-sectional, ou seja, os dados refletem um recorte pontual no tempo, que se referem ao período em que foram coletados. (SEAKARAN, 1992)

A Região Litoral do Paraná foi escolhida em função do acúmulo de conhecimento prévio dos pesquisadores em relação a esse recorte espacial, além da adoção do critério de conveniência estatística para a viabilização da coleta de dados. Foram coletados e tratados dados primários, provenientes da pesquisa de campo e secundários derivados da revisão de literatura e análise documental. Os procedimentos de aproximação temática e coleta de dados foram programados para acontecerem em quatro fases: 1) consistiu em dar maior conhecimento aos pesquisadores com relação a fundamentação teórica, referentes as pesquisas no campo das redes sociais; 2) correspondeu à caracterização e contextualização da região objeto de análise, o que foi de suma importância, pois permitiu aos pesquisadores identificar e quantificar as unidades de análise que serviram de subsídio para a definição e distribuição amostral; 3) consistiu na compreensão de como se dá o processo de atuação da instância de governança; 4) envolveu a coleta e análise de dados primários.

O procedimento que caracteriza a investigação como pesquisa de campo visou inquirir atores envolvidos com o turismo, quanto a intenção ou interesse em interagir uns com os outros para conformações de um projeto turístico, tomando por fundamento a sociometria tradicional (BASTIN, 
1966, FEGER, 2002; 2010). Como população para a coleta de dados, foram mapeadas 40 instituições. As unidades de análise identificadas se constituíram nos seguintes atores: Prefeituras Municipais, Secretarias de Turismo e Associações de Classe que representam os estabelecimentos privados. Por exemplo, ao invés de entrevistar todas as imobiliárias foi entrevistada a Associação das Imobiliárias, assim como das empresas, as associações Comerciais ou Câmaras de Dirigentes Lojistas. Entendeu-se que as entidades de classe, por serem representativas da categoria, atenderiam aos requisitos da pesquisa, considerando que são essas entidades que representam seus associados em ações de políticas públicas, no caso deste estudo, o programa de regionalização do turismo. Dada a pequena quantidade de unidades, pretendeu-se entrevistar todos elas, caracterizando a pesquisa como censitária e não amostral (MATTAR, 2008). Todavia, no período entre novembro de 2016 até janeiro de 2017, os formulários da pesquisa foram entregues pessoalmente pelos pesquisadores ou por e-mail, quando o indivíduo responsável pela instituição indicou que essa fosse a forma mais eficiente. Porém, apesar dos esforços da equipe, retornaram apenas 23 respondidos. Essa condição, implicou que a investigação passasse a ser caracterizada como amostral não-probabilística, visto que os respondentes não foram selecionados por métodos aleatórios (MATTAR, 2008). Este fato, segundo o referido autor, não inviabiliza a pesquisa, porém impõe restrições quanto a generalização das suas constatações. Todos os entrevistados constam do Quadro 1, exceto o Ministério do Turismo e Universidades os quais também constam no referido quadro porque foram citadas pelos demais respondentes, e precisam constar na matriz para geração do grafo representativo da rede, entretanto, não se disponibilizaram a participar da pesquisa, portanto não são parte da amostra.

O Quadro 1, foi elaborado para facilitar a alocação dos atores no Grafo (Figura 2) representativa da rede e servir como legenda para a identificação das entidades respondentes e citadas na coleta de dados. 


\section{Quadro 1. Legenda atores entrevistados e citados constantes no grafo}

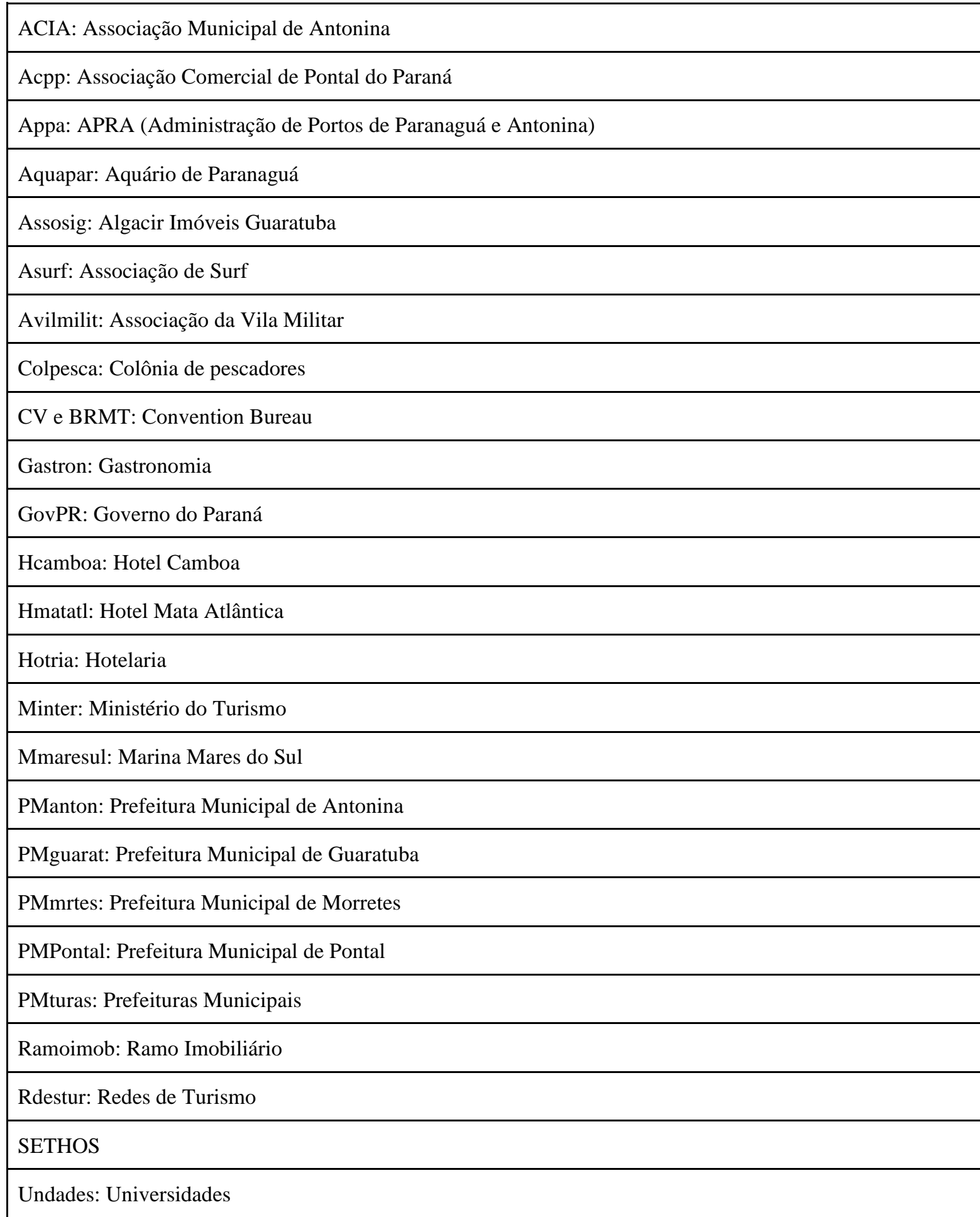

Fonte: Autores da pesquisa

Observatório de Inovação do Turismo - Revista Acadêmica

Vol. XIII, n 3 , dezembro - 2019 
Os dados colhidos ao longo do processo da pesquisa foram organizados em diagramas de relacionamento, utilizando o software UCINET, cujo suporte permitiu a elaboração dos seguintes indicadores: grau de centralidade; índice de centralização; grau de intermediação e grau de proximidade, os quais são descritos na seção seguinte deste artigo.

\section{Resultados}

Apresenta-se, nesta seção, os resultados obtidos com a aplicação da pesquisa. Inicia-se com a apresentação da região objeto de análise e, em seguida, prossegue-se com os dados relacionados com a interação dos atores que atuam na área.

A Região Turística Litoral do Paraná (Figura 1) está localizada a aproximadamente $100 \mathrm{~km}$ da Região Metropolitana de Curitiba, capital do Paraná, possui $6.061,2 \mathrm{Km}^{2}$ de superfície, que representam 3\% do território paranaense. É composta por 7 municípios: Antonina, Guaraqueçaba, Guaratuba, Matinhos, Morretes, Paranaguá e Pontal do Paraná. Apresenta grande diversidade cultural e natural, que "evidenciam seu potencial turístico e a caracterizam como polo indutor do desenvolvimento turístico estadual”, principalmente porque os atrativos turísticos geralmente mobilizam o deslocamento da população visitante para atividades de descanso e lazer (SET, 2010, p. 25; PIERRI et. al., 2006).

Figura 1. Localização do Polo Turístico Litoral Paranaense

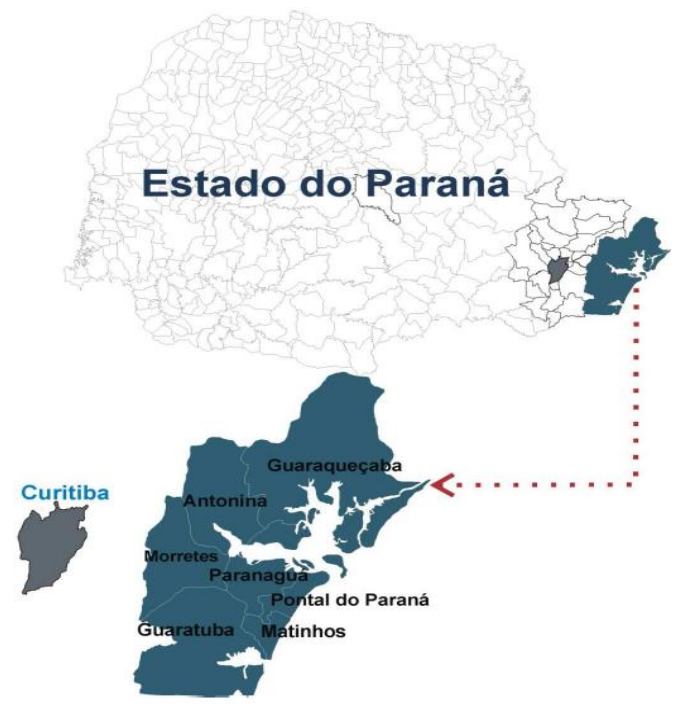

Fonte: Secretaria Estadual de Turismo (2010, p. 25) 
Dentre os 7 municípios da região, apenas um não é marítimo, o de Morretes, e, conformam a segunda menor extensão litorânea brasileira. Já Antonina e Paranaguá possuem tradição portuária, sendo que esse último, representa um dos mais importantes portos de cargas do Brasil. Os municípios praieiros são Guaratuba, Matinhos e Pontal, todos eles com forte ênfase nas segundas residências turísticas. (PIERRI et. al., 2006).

Em termos de atrativos turísticos, existe uma diversidade considerável na região. No que tange ao elemento natural, $82 \%$ da área territorial é caracterizada como Unidades de Conservação, preservando importante remanescente da Mata Atlântica brasileira. Em função dessa característica e da presença das Serras do Mar e da Prata, grande parte dos atrativos é natural, incluindo as praias e baías. Além disso, a ocupação do litoral sul preserva em grande medida sua história na região, o que se manifesta em três municípios com centro histórico de expressivo valor patrimonial e turístico (Antonina, Morretes e Paranaguá) (ABRAHÃO e BAHL, 2011; PIERRI et. al., 2006; SET, 2010).

O diagnóstico da Cadeia Produtiva do Turismo no Litoral (IPARDES, 2008) identificou a predominância das micro e pequenas empresas, o baixo grau de capacidade associativa e de confiança interorganizacional e interinstitucional, bem como a delegação ao Estado, em vários níveis, da responsabilidade pelas ações relacionadas ao desenvolvimento. Mediante as comentadas características geográficas, a atividade turística possui bastante relevância na região.

Segundo a literatura revisada, especialmente nos argumentos de Putnam (1996) e Fischer e Melo (2004) o nível de relacionamento entre os atores é primordial para o desenvolvimento de uma região. No caso do turismo, Pimentel e Pimental (2012) destacam que o nível de interação e de confiança entre os atores é importante para o atendimento do mercado. Diante disso, apresentam-se, a seguir, os indicadores, bem como, o diagrama formado pelo relacionamento indicado pelos respondentes da pesquisa.

Para permitir observar visualmente o nível de relacionamento ocorrido entre os atores, recorrese aos grafos Figura 2. 
Figura 2. Mapa das relações sociais entre atores do turismo da Região Litoral do Paraná

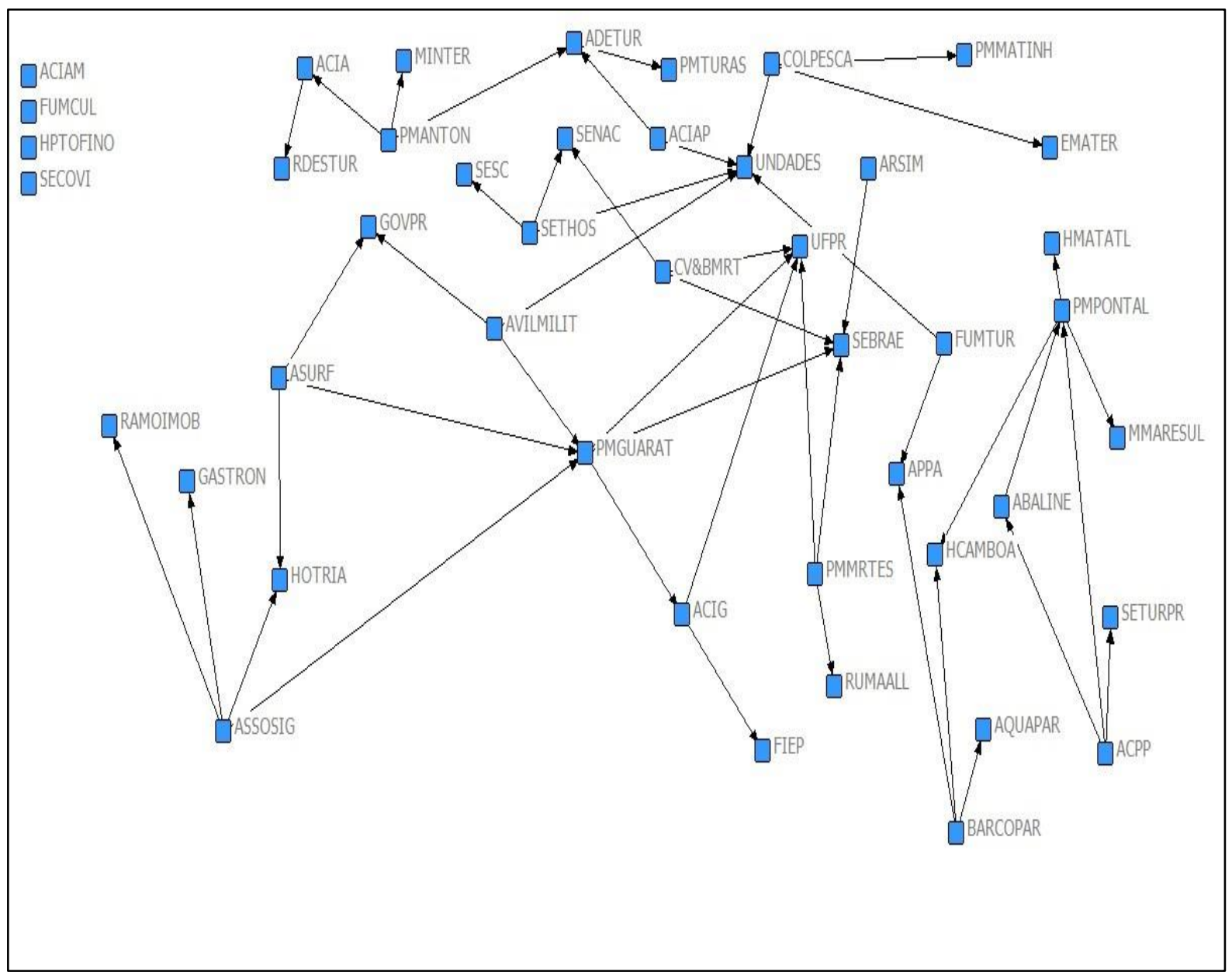

Fonte: Autores da pesquisa

No caso desta investigação, com o tratamento dos dados por meio do software UCINET, foi possível demonstrar visualmente o nível de relacionamento entre os atores, dando origem a Figura 2. Como se verifica na imagem, o relacionamento entre os atores não forma uma rede densa. É possível identificar também pelo sentido das setas, que os parceiros potenciais (com quem cada um tem interesse e pretensões de parcerias) mais citados para projetos de turismo regional são as universidades, de maneira geral, e a Universidade Federal do Paraná (UFPR), em particular. Um terceiro ator significativamente referenciado é o Serviço Brasileiro de Apoio às Micro e Pequenas Empresas (SEBRAE), entidade de apoio ao empresariado. Identificou-se que a maioria das 
A REGIONALIZAÇÃO DO TURISMO NO

LITORAL DO PARANÁ (BRASIL): ANÁLISE DA REDE DE INTERAÇÃO ENTRE OS STAKEHOLDERS
Jose Elmar Feger

Cinthia Maria de Sena Abrahão

Jose Manoel Gonçalves Gândara

Carlos Rogelio Virgen Aguilar

associações citou como principais parceiros as prefeituras, secretarias e as universidades. Já os atores privados, bem como as Prefeituras e respectivas Secretarias, citaram outras empresas privadas (principalmente do ramo de hotelaria), além das universidades.

Questionados sobre as razões para a escolha dos atores a fim de realizarem ações conjuntas, as prefeituras e secretarias foram citadas como as principais parceiras por oferecerem benefícios, tais como o investimento, auxílio financeiro, estrutura e recursos para a divulgação. Já as universidades foram citadas pelo seu potencial em geração de conhecimento, realização de pesquisas, trabalhos técnicos e sociais, troca de experiências e o curso de turismo. As empresas privadas, composta em sua maioria por atores do ramo da hotelaria, foram citadas por oferecerem: eventos, divulgação e patrocínios. Essas justificativas condizem com os argumentos apresentados por Olave e Amato Neto (2005) ao afirmarem que as organizações se juntam com vistas à otimização de recursos. No que tange a indicação de entidades públicas como atores a serem convidados para parcerias, evidencia-se o que já foi identificado por IPARDES (2008), que afirma que persiste o comportamento social de delegação ao Estado das responsabilidades referentes ao processo de desenvolvimento.

Visando ampliar o entendimento, um indicador a ser analisado é o nível de relacionamento existente entre os atores envolvidos com o turismo. No caso investigado, destaca-se que ocorre um reduzido grau de consistência da rede, visto que o índice calculado para o número de relacionamentos que ocorrem entre os atores que responderam à pesquisa é de $2,4 \%$, indicando que a densidade da rede é baixa, confirmando o que já pôde ser notado ao analisar a Figura 2. Esse fato pode indicar que há dificuldades na região para que se configure como uma Rede Estratégica Regional - RER (LUNDBERG, 2011; BALESTRIM; VERSHCHOORE E REYES JÚNIOR (2010; 2016)), e obtenha os benefícios relativos ao grau de compartilhamento da cultura comum e de valor, possibilitando ampliar o repartimento de recursos, conhecimento e trabalho (CHIM-MIKI; BATISTA-CANINO (2017). Ou mesmo, a geração de potencial inovativo por meio da viabilização de estratégias coletivas de inovação e o estabelecimento de um ambiente propício ao aprendizado (RITALA, 2012).

Além de tal imagem, por meio do UCINET, foi possível calcular indicadores estatísticos. No caso, dos atores mais citados, o software forneceu o grau de centralidade que pode ser observado no Quadro 2. Verifica-se que apesar de receber um maior número de citações por parte dos demais atores entrevistados, o grau de centralidade destes atores é bastante baixo. Nesse aspecto, tratados de maneira geral, universidades (exceto a UFPR) obtêm o índice 0,114; tanto a Universidade Federal do Paraná (UFPR) e como o SEBRAE 0,091 e a Prefeitura Municipal de Guaratuba com 0,068. 
Quadro 2. Grau de centralidade dos atores

\begin{tabular}{|l|c|c|}
\hline \multicolumn{1}{|c|}{ Atores } & $\begin{array}{c}\text { Quantidade de } \\
\text { Relações }\end{array}$ & Índice \\
\hline Universidades & 5 & 0,114 \\
\hline Universidade Federal do Paraná & 4 & 0,091 \\
\hline SEBRAE & 4 & 0,091 \\
\hline Prefeitura Municipal de Guaratuba & 3 & 0,068 \\
\hline
\end{tabular}

Fonte: Autores da pesquisa

Esses números confirmam o que é observado na imagem Figura 2, que os atores com os maiores graus de centralidade são as universidades, de modo geral, que contêm cinco relações (COLPESCA, ACIAP, SETHOS, AVILMILT e FUMTUR). Isso pode indicar que os atores atribuem importância especial ao ambiente acadêmico para o desenvolvimento do turismo, particularmente, em função de aportarem conhecimento. Esse fato está em acordo com o que apontam Casarotto Filho e Pires (2001), segundo os quais para ocorrer o desenvolvimento da rede regional é importante a existência e integração das universidades com os demais atores. As ligações com ênfase para a UFPR, foram indicadas pelos atores CV\&BMRT, PMGUARAT, ACIG, PMMRTS, justificada por eles pelo apoio oferecido nas áreas de conhecimento e pesquisa, trabalhos técnicos e sociais. O SEBRAE também é citado (CV\&BMRT, PMGUARAT, PMMRTS, ARSIM) e tem o mesmo número de relações que a Universidade Federal do Paraná. Segundo os entrevistados, os benefícios que o SEBRAE pode oferecer como parceiro são: apoio financeiro, apoio técnico e estrutura. A Prefeitura Municipal de Guaratuba obteve ao todo três citações (AVILMILT, ASURF, ASOSIG), os inquiridos indicaram que os benefícios que a prefeitura oferece são: infraestrutura, apoio em massa e o envolvimento do município, o que também pode ser resultado de experiências anteriores, indicando o aprofundamento do relacionamento da Prefeitura Municipal de Guaratuba com os atores, sendo essa a que possui maior número de relações. (OLAVE; AMATO NETO, 2005).

O maior grau de relação ser cinco constitui um fator preocupante do ponto de vista do ambiente para o desenvolvimento, considerando que as redes são responsáveis por coordenar a estrutura básica da atividade turística. E com base na imagem gerada pelo UCINET, percebe-se que não há interações intensas na região. Segundo as linhas de pensamento de Putnam (1996) e de Fisher (2004), a cooperação entre os atores é uma ferramenta valiosa no desenvolvimento político e socioeconômico da região. A análise dos graus de centralidade explicita que os atores não enxergam a grande rede em que estão e possuem uma ideia vaga de como poderiam contribuir com o desenvolvimento do turismo e da região, e de quem seriam seus parceiros, já que alguns atores não 
citaram nenhum estabelecimento no questionário aplicado. Há também que se ponderar as questões de coopetição, importante para o desenvolvimento dos destinos turísticos, que ficam debilitadas devido ao pouco entrosamento dos atores locais, conforme explicitam Chim-Miki e Batista-Canino (2017).

Um outro indicador calculado pelo software foi o grau de proximidade. Esses indicadores são apresentados no Quadro 3. O grau de proximidade indica a capacidade de um nó de se ligar com todos os atores da rede. Quanto maior o indicador maior a capacidade do ator social se ligar aos demais nós, quanto menor o indicador menor a capacidade de se relacionar com os outros atores. Diante disso, foram analisados os índices de entrada e de saída dos atores. Como demonstram os dados, o grau de entrada dos atores oscila entre 0,280 e 0,267, os demais atores analisados, que não constam no referido quadro, ficaram com um índice de entrada e de saída por volta de 0,263 à 0,250.

Quadro 3. Grau de proximidade dos atores

\begin{tabular}{|l|c|c|}
\hline Atores & Grau de Entrada & Grau de saída \\
\hline Algacir Imóveis Guaratuba & 0,280 & 0,250 \\
\hline Associação da Vila Militar & 0,275 & 0,250 \\
\hline Associação do Surf & 0,275 & 0,250 \\
\hline Associação Comercial de Pontal do Paraná (ACPP) & 0,273 & 0,250 \\
\hline Prefeitura Municipal de Antonina & 0,270 & 0,250 \\
\hline Prefeitura Municipal de Guaratuba & 0,267 & 0,263 \\
\hline
\end{tabular}

Fonte: Autores da pesquisa

Da mesma forma que nos outros indicadores já mostrados, as associações e Prefeituras se destacam. No Quadro 3, observa-se um ator privado (“Algacir Imóveis Guaratuba”), porém essa distância não é muito significativa, devido a rede ser pouco densa. Em resumo, não há grande proximidade entre os atores envolvidos e, considerando o número de respondentes, não há muita diferença entre os níveis de proximidade dos atores envolvidos. Uma vez que o número de relações indica a proximidade dos atores (LIMA , 2018), evidencia-se que os atores atuam de forma mais isolada e não coletiva.

Para verificar que atores possuem a condição de promover os relacionamentos entre os stakeholders da rede, calculou-se grau de intermediação entre os atores, que consta no Quadro 4. 
Quadro 4. Grau de intermediação entre os atores

\begin{tabular}{|l|c|c|}
\hline \multicolumn{1}{|c|}{ Atores } & Quantidade de Relações & Índice \\
\hline Prefeitura Municipal de Guaratuba & 12 & 0,634 \\
\hline Prefeitura Municipal de Pontal & 6 & 0,317 \\
\hline Associação Comercial de Guaratuba (ACIG) & 4 & 0,211 \\
\hline Associação de Desenvolvimento do Turismo (ADETUR) & 2 & 0,106 \\
\hline Associação Comercial de Antonina (ACIA) & 1 & 0,053 \\
\hline
\end{tabular}

Fonte: Autores da pesquisa

Segundo o que se observa Quadro 4, as prefeituras de Guaratuba e Pontal possuem os maiores potenciais para intermediar possíveis conflitos e necessidades dos demais atores. As prefeituras, de acordo com os dados coletados, podem ser os principais elos com os outros atores. Entende-se que tal posição relaciona-se ao fato de possuírem alcance municipal e por serem os responsáveis pelas políticas de turismo no município, podendo inclusive, se constituir em parceiras em prol de eventos e apoio financeiro para projetos. As associações no geral, por se caracterizarem como representantes de setores, apoiam ações, geralmente, de acordo com os seus segmentos. A ADETUR, por sua vez, que é a associação responsável estritamente pelo desenvolvimento do turismo, deveria ter um maior número de citações, tanto em nível de centralização como de intermediação, por ser a instância de governança da região. Esse fator pode indicar que a entidade precisa ampliar sua atuação para que possa desempenhar o papel necessário ao desenvolvimento regional do turismo, conforme consta na Política de Regionalização do Turismo. Esse aspecto reforça o que foi identificado em estudos anteriores (IPARDES, 2008) de que as instituições públicas nos vários níveis são consideradas mais interessantes para obter apoio ao desenvolvimento regional.

Nesta seção, foram apresentados os indicadores elaborados com base na pesquisa efetuada, bem como apresentado o grafo contendo a representação dos nós e ligações que ocorrem entre os atores. Constatou-se que não há um volume significativo de ligações, nem de interações entre os atores locais no que concerne ao desenvolvimento do turismo. 
A REGIONALIZAÇÃO DO TURISMO NO

LITORAL DO PARANÁ (BRASIL): ANÁLISE DA

REDE DE INTERAÇÃO ENTRE OS

STAKEHOLDERS
Jose Elmar Feger

Cinthia Maria de Sena Abrahão

Jose Manoel Gonçalves Gândara

Carlos Rogelio Virgen Aguilar

\section{Considerações finais}

O estudo que originou esse artigo teve como principal propósito compreender e determinar a importância que os atores sociais possuem na configuração do turismo na Região Turística Litoral do Estado do Paraná. Como visto na literatura consultada para a investigação, o nível de relacionamento dos atores é importante para que haja desenvolvimento do turismo e que se promova a inovação. Nesse sentido, conhecer quem são os atores e como interagem é importante para se elaborar estratégias ao desenvolvimento do turismo.

A partir dos dados, compreende-se que os níveis de interação existentes entre os atores são baixos, e que buscam o apoio para seus projetos nas instituições públicas, especialmente as prefeituras municipais. No que concerne a importância dos atores, verificou-se que três grupos se destacam, as universidades, de maneira geral, e a UFPR, bem como, o SEBRAE, os quais aparecem como principais fontes de apoio para conhecimento, elaboração de projetos e recursos. No caso, as prefeituras e associações de classe possuem importância mais no sentido de intermediar as ligações, visto que apareceram com maiores índices neste quesito.

Apesar de não se ter conseguido entrevistar a população de entidades que atua na região, com a amostra obtida foi possível elaborar os indicadores pretendidos, possibilitando alcançar o objetivo da pesquisa.

Conclui-se que, apesar de não possuírem um grau de centralidade significativo, as municipalidades revelam ser importantes elos entre os atores regionais. Destacam-se as universidades e o SEBRAE como elementos importantes e centralizadores da rede. Além disso, observa-se pouca representatividade da instância de governança, que fica em quarto lugar no ranking dos atores identificados como pontes entre os demais envolvidos com o turismo regional.

Contudo, segundo Martins et al (2009), os atores articulados em rede são os maiores responsáveis pelo desenvolvimento do turismo. Embora a rede identificada seja pequena e ainda não apresente o nível de relações ideais, ao menos a existência da instância de governança pode contribuir para o adensamento da rede, no sentido de provocar a interação em busca de desenvolver o turismo e a região em que estão localizados. A cooperação entre eles é essencial, já que, segundo Pimentel e Pimentel (2012), o turismo é uma rede feita de diversas ações por diferentes atores, que incluem as prefeituras e secretarias, associações, instituições de ensino e atores privados, responsáveis por fornecer desde os recursos básicos para uma região, até os recursos especializados e segmentados do ramo do turismo. O turismo é um conjunto de várias ações e o desenvolvimento do setor é resultado 
das interações dos atores da região, pois sem a comunicação entre eles, o desenvolvimento do turismo e da região permanecem estáticos.

Com a investigação, foi possível obter percepções concretas a respeito da dinâmica de relações ente os atores. Destaca-se que os atores mais citados não necessariamente são os que permitem a maior facilidade de comunicação entre os demais. Pelos resultados apresentados, as universidades e o SEBRAE são as entidades mais citadas pelos respondentes, porém ao se calcular os índices de intermediação são as prefeituras e associações comerciais que possuem um maior índice. Esses aspectos são interessantes e importantes para se entender o processo de relacionamento entre os responsáveis pelo desenvolvimento do turismo regional. Por essa razão, visto que o estudo aqui apresentado se baseia em um caso único, seria importante ampliar o número de pesquisas, aplicando a mesma metodologia em outras regiões a fim de ampliar a consistência e permitir extrapolação de resultados para o setor de turismo como um todo.

\section{Referências}

ABRAHÃO, C. S.; BAHL, M. (2011). Turismo cultural e desenvolvimento includente: o caso de Paranaguá, Paraná, Brasil. IN: Turismo em Análise, v. 22, n. 1, 2011.

BALESTRIN, A.; VERSCHOORE, J. R.; REYES JÚNIOR, E. O campo de estudo sobre rede de cooperação interorganizacional no Brasil. Revista de Administração Contemporânea, Curitiba, v. 14, n. 3, p. 458-477, 2010.

BALESTRIN, A.; VERSCHOORE, J. R.; REYES JÚNIOR, E. Redes de cooperação empresarial. 2. ed. Porto Alegre: Bookman, 2016.

BASTIN, G. As técnicas sociométricas. Lisboa: Moraes Editores, 1966.

BERNARDES, A. T; ALBUQUERQUE, E; RUIZ, R. M; RIBEIRO, L. C. Modelling the role of national system of innovation in economical differentiation. In: 8th Granada seminar on computational and statistical physics (modeling cooperative behavior in the social sciences), 2005, Granada. Proceedings. New York: AIP, 2006.

BOULLÓN, R. C. Planejamento do espaço turístico. Bauru: Edusc, 2002.

BOULLÓN, R.C. Os municípios turísticos. Bauru: Edusc, 2005. 
BRASIL, Ministério do Turismo. Regionalização. Disponível em: <http://www.turismo.gov.br/turismo/programas_acoes/regionalizacao_turismo/>. Acesso em: $07 / 06 / 2015$.

BRASIL. MTUR. Ministério do Turismo. Plano Nacional de Turismo - O turismo fazendo muito mais pelo Brasil: 2013-2016. Brasília/DF: MTUR, 2013. Disponível em http://www.turismo.gov.br/export/sites/default/turismo/o_ministerio/publicacoes/downloads_publicac oes/plano_nacional_2013.pdf. Acesso em janeiro de 2014.

BURT, R. S.; KILDUFF, M.; TASSELLI, S. Social network analysis: foundations and frontiers on advantage. Annual Review of Psychology, v. 64, p. 527-547, 2013.

CASAROTTO FILHO, N.; PIRES, L. H. Redes de pequenas e médias empresas e desenvolvimento local. 2. Ed. São Paulo: Atlas, 2001.

CHIM-MIKI, A.; BATISTA-CANINO, R.M. A associação baseada em coopetição nas redes interorganizacionais do turismo: uma comparação entre Curitiba e Foz do Iguaçu, Brasil. Revista Brasileira de Gestão de Negócios, São Paulo, v. 19, n. 64, abr/jun 2017, p. 219-235.

A pesquisa sobre coopetição: em direção a uma melhor compreensão do construto e sua aplicação no turismo. Revista Turismo - Visão e Ação - Eletrônica, Vol. 18 - n. 3 - set. - dez. 2016, p. 424-447.

CRESWELL, J. W. Projeto de pesquisa: métodos qualitativo, quantitativo e misto. Porto alegre: Artmed, 2012.

DE LA TORRE, O. El turismo: fenómeno social. 2 ed. México: Sociología, Fondo de Cultura Económica, 1997.

FEGER, J. E. (2010). Regionalização do Turismo na área de influência dos municípios de Marcelino Ramos (RS) e Piratuba (SC). Tese (Doutorado em Desenvolvimento Regional). Universidade de Santa Cruz do Sul (Unisc), 2010.

FEGER, J. E. Turismo e desenvolvimento regional: o caso do Meio-Oeste catarinense. 2002153 p. Dissertação (Mestrado em Desenvolvimento Regional) - Ciências Humanas e da Comunicação. Universidade Regional de Blumenau, Blumenau, 2002.

FEGER, J. E.; ABRAHAO, C. M. S. ; ETGES, V. E. . Redes sociais como fundamento para o desenvolvimento turístico: análise do caso dos centros turísticos de Piratuba e Treze Tílias, Santa Catarina, Brasil. Cultur: Revista de Cultura e Turismo, v. 2, p. 29-51, 2015.

FERRÃO, J. Inovar para desenvolver: o conceito de gestão de trajetórias territoriais de inovação. In: Revista Internacional de Desenvolvimento Local, v.3, n.4, 2002, p.17-26.

FISCHER, T.; MELO, V. P. Organizações e interorganizações na gestão do desenvolvimento sócioterritorial. Revista Organização e Sociedade. Salvador: EAUFBA, V. 11, 2004. 
FREEMAN, L. Centrality in social networks conceptual clarification. Social Networks, v. 1, n. 3, p. 215-239, 1978.

FREEMAN, L. The development of social network analysis. A Study in the Sociology of Science, v. $1,2004$.

FREIRE, J. R. S., FARINA, M. C., PASCOTTO, S. M. P., SANTOS, I. C. Busca do conhecimento técnico científico: análise de rede informal Interorganizacional. In: Revista de gestão e projetos GEP, 2014.

GÂNDARA, J. M; TORRES, E.; L. D. A participação de todos os "atores" no processo turístico. In: Anais do I Seminário de Pesquisa em Turismo do Mercosul. Universidade de Caxias do Sul, Caxias do Sul, RS, Brasil.,(2003.

GERHARDT, T.E.; SILVEIRA, D.T. (org). Métodos de pesquisa. Ed. UFRGS, $1^{\text {a }}$ Ed. Porto Alegre, 2009.

GIL, A. C. Como elaborar projetos de pesquisa. 5 ed. São Paulo: Atlas, 2010

GRAY, D. E. Perspectivas teóricas e metodologias de pesquisa. In: . Pesquisa no mundo real. Porto Alegre: Penso, 18-37. 2012.

IPARDES. Instituto Paranaense de Desenvolvimento Econômico e Social. Cadeia produtiva do Turismo no Paraná. Curitiba: IPARDES, 2008.

KÖRBES, C.; FEGER, J. E. Atores e redes sociais na gestão de políticas públicas de juventude em Curitiba/PR. Contemporâneos. Revista de Artes e Humanidades, v. 18, p. 1-32, 2018.

LIMA, T. Teorias das redes interorganizacionais no turismo: uma análise sociométrica da rede de turismo de eventos de Juiz de fora (MG) para o trabalho do Convention \& Visitors Bureau do destino. Dissertação. Programa de Pós-Graduação Strictu Sensu em Turismo. Universidade Federal Fluminense. Niterói. Rio de Janeiro, 2018

LUNDBERG, H. Challenges, complexities and advantages of regional strategic networks. In: JOHANSON, M.; LUNDBERG H. Network strategies for regional growth. Houndmills. Basingstoke: Palgrave Macmillan, 2011, p. 229-238.

MALHOTRA, N. Pesquisa de marketing uma orientação aplicada. Porto Alegre. Bookman, 2006.

MARTINS, D. A; NETO, P. M. S; SANTOS, E. M; ARAÚJO, G. H. A; CAMPOS, A. J. M. Arranjos produtivos locais: retrospectiva e tendências na perspectiva das operações de serviços. IN: Anais do Simpósio de Engenharia de Produção, 2009, 16. Anais... Bauru/SP, 2009.

MATTAR, F. N. Pesquisa de marketing edição compacta. São Paulo: Atlas, 2008. 
OLAVE, M. E. L; AMATO NETO, J. Redes de cooperação produtiva: uma estratégia de competitividade e sobrevivência para pequenas e médias empresas. In: Gestão \& Produção, v.8, n.3, dez. 2005, p. 289-303.

OLIVEIRA, N.; DE SOUZA, D. L.; DE CASTRO, C. C. Análise sociométrica da rede de relacionamento das bibliotecas que constituem o Consórcio das Universidades Federais do SulSudeste de Minas Gerais. Perspectivas em Ciência da Informação, v. 19, n. 1, p. 130-148, 2014.

PANOSSO NETTO, A. What is tourism? Definitions, Theoretical Phases and Principles. In: TRIBE, J. (Ed.). Philosophical Issues in Tourism. Londres: Channel View Publications, v. 1, p. 43-62, 2009.

PEARCE, D. G. Geografia do turismo: fluxos e regiões no mercado e viagens. São Paulo: Aleph, 2003. 134

PEARCE, D. G.; SCHÄNZEL, H. A. Destinations: tourists' perspectives from New Zealand. International Journal of Tourism Research, 17, p. 4-12, 2013.

PIERRI, N.; ANGULO, R. J.; SOUZA, M. C.; KIM, M. K.. A ocupação e o uso do solo no litoral paranaense, conflitos e tendências. IN: Desenvolvimento e Meio Ambiente, n.13, p.137-167, 2006.

PIMENTEL, T.D. ; PIMENTEL, M. P. C. . Destino turístico como construção coletiva: os atores envolvidos e sua necessidade de articulação. In: Congresso Latino-Americano de Investigação Turística, 2012, São Paulo.

PUTNAM, R. D. Comunidade e democracia: a experiência da Itália moderna. Rio de Janeiro: Editora Fundação Getúlio Vargas, 1996.

RITALA, P. Coopetition Strategy - When is it Successful? Empirical evidence on innovation and market performance. British Journal of Management, v. 23, 2012, p. 307-324.

RODRÍGUEZ, R. M.; FERNÁNDEZ, J. I. P. Desarrollo turístico y dinámica relacional. Metodología de análisis para la gestión activa de destinos turísticos. In: Cuadernos de Turismo, n. 23, p. 173-193, 2009.

SANTALOYA-SANZ, J.; MORA-VALENTÍN， E.; ORTIZ-DE-URBINA-CRIADO, M. Tension management and capabilities in coopetition. Revista Espacios, v. 38,n. 14, 2017, p. 8-22.

SCHMITT, C.J.. Redes de atores e desenvolvimento rural: perspectivas na construção de uma abordagem relacional. DOSSIÊ - Sociologias, Porto Alegre, Ano 13, n.27, maio/ago 2011, p. 82-112.

SCOTT, N,; BAGGIO, R.; COOPER, C. Network analysis and tourism: from theory to practice. Channel View Publications, 2008.

SEAKARAN, U. Research methods for business: a skill-bulding approach. 2 ed. New York: Juhn Willey, 1992. 
SET. Secretaria de Estado e do Turismo. (2010). Plano de desenvolvimento integrado do turismo sustentável: PDITS - Polo Turístico do Litoral Paranaense. Disponível em: < http://www.turismo.pr.gov.br/arquivos/File/setu/pdf/institucional/PDTISProdutoLitoral.pdf $>$. Acesso em $12 / 05 / 2015$

VÁZQUEZ, A. V. Dinámica relacional de la gestión turística en el pueblo mágico de Calvillo, Aguascalientes, Mexico. Teoría Y Praxis, p.137-160, 2013.

XAVIER, T. R. et al. A relação entre redes e turismo: uma análise bibliométrica sobre a emergência de um novo paradigma no planejamento turístico. In: Turismo \& Sociedade. Curitiba, v. 5, n.2, outubro de 2012, p. 443-465. 